\title{
XIII Festival Internacional de Música Contemporánea
}

Entre el lunes 14 y el viernes 18 de enero de 2013 se desarrolló una nueva versión del XIII Festival Internacional de Música Contemporánea que organiza el Departamento de Música y Sonología de la Facultad de Artes de la Universidad de Chile. Se inauguró por Luis Orlandini, Director del Departamento de Música y Sonología, quien destacó el hecho que esta fuera la trigésima versión desde que este evento se reinstalara el año 2000. En tal sentido se alcanzó el año 2013 un punto de coincidencia con las trece versiones de los antiguos Festivales de Música Chilena en el pasado siglo XX. A partir de este equilibrio numérico se abren posibilidades de realizar balances y reflexiones necesarias para el desarrollo de este Festival.

En la inauguración estuvieron presentes autoridades de la Facultad de Artes así como diversos Premios Nacionales de Arte en Música y fue Eduardo Cáceres, Director Artístico del Festival, quien se dirigió a continuación al público. Resaltó que este año los invitados fueron compositores-musicólogos en lugar de intérpretes o ensambles extranjeros, todos ellos latinoamericanos. Estos invitados ofrecieron cinco charlas en horario previo a los conciertos, las cuales entendemos que fueron provechosas y con buen público, todo un logro, debido al horario en plena época de verano en el país.

La primera jornada se caracterizó por un espíritu institucional y un tono emotivo, el que se inició con un homenaje a Federico Heinlein, quien en palabras de Luis Merino se destacó por haber logrado una justa relación de la música con "la magia de la palabra". Asimismo, Valene Georges, Directora del Ensemble Bartok, recordó con especiales palabras al compositor antes de que interpretaran su Oda al día Feliz (1998), definida por ella como un "compendio del pensamiento musical de Heinlein". Un segundo homenaje, al final de la primera parte, al destacado maestro Luis Advis, reafirmó este carácter rememorativo, con la presentación de extractos de su Cantata Santa María de Iquique (1969) por un grupo de catorce intérpretes, estudiantes de Teoría de la Música, Composición, Interpretación y Actuación Teatral de esta casa de estudios. La introducción estuvo a cargo de Rodrigo Torres, quien al mencionar a personas cercanas a Advis generó un momento de íntimo recuerdo. Señaló que en esta misma Sala Isidora Zegers, anteriormente sala conocida como La Reforma, hace 42 años se realizó la primera audición de Cantata, con posterioridad a su estreno en el Estadio Chile. Puede resultar complejo pensar la relación entre esta obra de Advis y el contexto que supone un festival de música contemporánea, en lo que se busca la puesta al día con las propuestas actuales del arte musical. Sin embargo, al escuchar la música y los versos de la Cantata, es la experiencia de la obra la que habla por sí misma. Se actualizó por lo tanto y resultó natural hacer la relación con lo que sucedía esos mismos días de enero entre el pueblo mapuche y la sociedad chilena, por mencionar un ejemplo.

Este año el Festival se destacó por sobre lo habitual por el numeroso público que llegó a cada concierto. Hubo algunos días en que la capacidad de la Sala Isidora Zegers, tanto en el primero como segundo piso, estuvo desbordada. Este público escuchó atentamente veintisiete obras en dicha sala -más los extractos de la Cantata de Advis- y cuatro obras en el Teatro de la Universidad de Chile. De este total, veintiuna obras pertenecieron a compositores chilenos, seis obras a autores europeos, solo tres obras a músicos latinoamericanos y una obra a Japón. De ellas, once obras fueron para grupos pequeños -solos, dúos y un trío- y las demás fueron para agrupaciones más numerosas, desde cuartetos hasta ensambles instrumentales. Como ya es habitual, primaron los estrenos, de los cuales seis fueron estrenos en Chile y trece estrenos absolutos. La mayoría de las obras fueron compuestas en este siglo XXI, sobre todo en los últimos años. Como compositores de referencia estuvieron presentes Pierre Boulez con su obra Douze Notations (1945) -de la cual la intérprete curiosamente no incluyó Revista Musical Chilena, Año LXVII, enero-junio, 2013, Nº 219, pp. 143-146 
la característica número seis-; Smith Brindle con la pieza para guitarra sola El Polifemo de oro (1956) sólidamente ejecutada por Gonzalo López y la Sonata para flauta y guitarra (1975) de Rautavaara. Luego, una gama variada con dos obras de los años 80 y cuatro de los años 90.

Resalta la mínima presencia de obras con electrónica, solo hubo dos, de Edgardo Cantón y Daniel Osorio, quienes incorporan normalmente en su música electrónica en tiempo real. En cuanto a obras que recurrieron a la voz, hubo cuatro en esta versión, dos de ellas corales. Respecto de los ensambles, hemos señalado en otras oportunidades que este Festival genera espacios a los conjuntos que trabajan permanentemente en torno al repertorio contemporáneo. Así, se pudo presenciar a los ensambles Compañía 1264, Taller de Música Contemporánea, Ensamble Bartók, Dakelyekant Ensamble de Percusión, Cuarteto Aulos, Copiu Ensamble Vocal y Coro Magnificat.

El ensamble Compañía 1264, importante iniciativa de esta Facultad, se llevó una buena parte del trabajo, con la presentación de seis obras en dos jornadas. El quinteto Compañía 1264 (2012) de Fernando Carrasco, de original estructura con fragmentos rápidos, pausas, gestualidades cambiantes, en tres movimientos breves, es un homenaje a sus tres maestros: Vila, Amenábar y Alcalde. Interesante obra, podría haber lucido más si la interpretación hubiera sido menos "cuidadosa" u ordenada. Una Canción (1998) del destacado invitado uruguayo Coriún Aharonián, es un quinteto con viola, y una obra curiosa que nos hace pensar en música de tipo incidental que relata una historia breve y lúdica. Para Del Puerto (2012) de Sebastián Ramírez fue necesario un cambio en la distribución del escenario, lo que resultó un tanto engorroso debido a la demora que causó. Septeto con piano, en un estilo algo indefinido, propone un trabajo con momentos enérgicos y pausas, liderados por una exigente parte de piano solista. Para la obra Tierra sonante (2011) del joven Juan Manuel Quinteros, una interesante pieza de forma libre y gestual, el ensamble se amplió a diez músicos, quienes generaron masas sonoras que se desplazaban en glissandos, interrumpidas por secciones más rítmicas que aludían a gestualidad del jazz o del teatro. De otra destacada invitada, Graciela Paraskevaidis, se presentó Libres en el sonido presos en el sonido (1997), un quinteto bien interpretado. Obra tránsica, con frases cíclicas construidas ya sea por grupos de notas rápidas o por largos tenutos, debido probablemente a lo largo de la pieza se perdió por momentos la atención del público. De Jorge Pepi-Alos, Esse Est Percipi (2012), septeto con el compositor al piano, de buen uso instrumental, hizo esperar un desenlace con frases largas y acordes quebrados, en los que se extrañó la presencia de silencios, más que de sonidos en forma ininterrumpida. Reconocemos el trabajo de su director Carlos Valenzuela, quien ha mejorado su técnica, y se presentó sólido y seguro. En adelante podría trabajar en pos de extraer una mayor expresividad en las interpretaciones del ensamble y de cada uno de sus músicos.

En cuanto a aportes al repertorio, se destaca la obra Tao (2011) de Fernando Munizaga, un sexteto vocal bien interpretado bajo la dirección de Rogelio González. Es un trabajo interesante. Con uso de fonemas en gestos de la mano que se abren y cierran con diferentes exigencias vocales. La obra Flotenquartett (2006) de Andrés Maupoint, en tres movimientos, exhibió una cuidadosa ejecución del cuarteto de flautas Aulos. De ritmo interno delicado, se mueve entre dinámicas piano, articulaciones eficaces y lograda escritura. Con algunas técnicas extendidas (voz, eólicos) fue apreciada por el público. Lo mismo sucedió con la obra del italiano Gabriele Manca, Movimiento parallelo (1998), quien ha estado en nuestro país en diversas oportunidades. Muy bien interpretada, al inicio le costó al público entrar en ella debido a su propuesta más innovadora en torno al silencio y a una exigencia en la escucha, pero luego fue seguida atentamente y la flauta contrabajo causó sensación entre los asistentes. Lástima que la acústica de la Sala Isidora Zegers no permita apreciar este tipo de obras sin recurrir a la amplificación, ya que lo que escuchamos se asemejaba por momentos a música electrónica más que a la propia idea del compositor.

La obra Chant d'Amour (2012), para 4 timbales de Boris Alvarado resultó un tanto monótona, si bien es dable destacar a Camila Sánchez, una joven solista que demuestra talento. En adelante puede buscar mayores contrastes dinámicos. Pregón (2012) de Rafael Díaz, con una estética más tonal y tradicional, instala la memoria y alusiones a imaginarios entre lo urbano y la naturaleza. Interpretada por un joven dúo de Viña del Mar, tuvo una buena acogida. Eduardo Cáceres, con Huija rendija (2011), presentó una revisión de material de una de sus Fantasías Rítmicas para piano, esta vez para cuarteto de guitarras. De carácter lúdico, fue recibida con entusiasmo. Respecto de Shadows (2011) de Patricio Wang, otro invitado, creemos que la idiomática utilizada no se acomodó a los intérpretes. Escuchamos a músicos de jazz tocando una obra de estilo poco definido que circulaba entre lo docto, lo contemporáneo y lo popular, lo que traslucía una cierta incomodidad y efectos poco logrados. Como clausura en la Sala Isidora Zegers se presentó la Cantata inmobiliaria (2011) de Miguel Letelier, con cerca de 30 
voces, dos baterías y piano, ante lo cual el escenario se hizo estrecho. Incorporó una puesta en escena y gestualidad del coro probablemente sugerida en la partitura. Si bien no siempre se entendió el texto, fue de gusto del público. De Juan Ortiz de Zárate, compositor invitado de Argentina y quien además dictó una charla, no pudo ser presentado su obra por razones de fuerza mayor.

El Dakelyekant Ensamble de Percusión de la Universidad de Chile resaltó por lo gestual y expresivo de una puesta en escena que interesó al público, en que los integrantes desarrollan una suerte de ritualidad, la que nos recuerda al grupo británico Stomp. Las obras que se interpretaron fueron Marimba espiritual (1983-84) de Minoru Miki y Danza bárbara (2002) de Jovan Zivkovic. Ellas resultaron ser demasiado extensas, hicieron disminuir el clímax logrado por el fervor de los intérpretes y, más allá de esta intensidad performativa, el valor musical disminuye en dos obras que son muy similares. El Taller de Música Contemporánea, participante habitual de este Festival, destacó a nivel de propuesta escénica por la obra Laquer (2012) de su director Pablo Aranda, que incluye objetos en el escenario para la producción de sonidos, logrados con el apoyo del equipo de "piso" de la sala. De buen resultado sonoro, por su estructura aleatoria mantiene alerta a los intérpretes durante su ejecución, lo que le produce una tensión musical que se transmite a los auditores. Interpretaron además de Daniel Osorio, la obra Ihuro (2009-2012), de delicada escritura, una de las dos composiciones con electrónica de esta versión del Festival.

Por segundo año consecutivo la función del último día se realizó en el Teatro de la Universidad de Chile con la importante participación de la Orquesta Sinfónica de Chile, en esta oportunidad de la mano de Francisco Rettig. Se inició con la Elegía (In memoriam Béla Bartók) para orquesta de cuerdas y percusión del maestro Cirilo Vila, a quien extrañamos entre los asistentes, estrenada el año $1982^{1}$. De cuidado estilo posromántico, se percibió poca precisión en su ejecución al inicio y en los pizzicati. La Sinfonía para instrumentos de viento (1920) de Stravinski se instaló como la obra de referencia del canon musical a partir del siglo XX. Destacaron los acordes logrados por los bronces y el buen trabajo de los vientos. Tal vez faltó vigor interno a la interpretación en la que extrañamos un mayor contraste entre las secciones rítmicas y las melódicas, características de este compositor ruso, en algunos momentos ejecutadas con tempos más lentos.

De los estrenos orquestales, en Dal-Al, Punto y línea (2012), el compositor Antonio Carvallo se distanció de su habitual escritura condensada y optó ahora por bloques de acordes, una escritura vertical y homogénea y un buen sentido de dramatismo. La repetición constante de masas sonoras en crescendo con sforzandos repentinos durante la totalidad de la obra hace que esta pierda algo de su efecto. Con un buen uso de colores de la orquesta, por momentos cuesta separar la música de la evocación a imágenes. En este sentido, el imaginario auditivo tan pregnante del cine afecta desde hace tiempo nuestra libre percepción de algunas obras orquestales. La Sinfonía de guerra (2003-2004) de Adrián Pertout, obra en dos movimientos que dio el cierre al Festival, resultó muy extensa, al parecer por los tempos más lentos de los indicados que eligió el director. Inspirada en la invasión que los Estados Unidos hiciera en Irak el año 2003 nos evoca igualmente un cierto estilo cinematográfico. Repite un mismo motivo rítmico durante todo el primer movimiento y utiliza, o tal vez abusa, de algunos clisés musicales que le hacen perder efectividad (¿o ganarla, en un público poco conocedor?). Su segundo movimiento resultó más atractivo, si bien hubiéramos esperado una mayor precisión en la orquesta. Al finalizar el programa la Orquesta Sinfónica fue calurosamente aplaudida por el público, nuevamente entusiasta por este cierre sinfónico.

Si debemos hacer algunas críticas, volvemos a insistir en que los programas deben ser hechos con mayor cuidado y detalle. En muchos casos no se especifican las instrumentaciones, jamás se indica el año de composición de las obras ni la fecha de nacimiento de los compositores -información relevante para una mejor apreciación y futuros estudios-y, mención aparte se llevan las curiosas categorías para definir los tipos de estrenos. En cuanto a la amplificación, más sutil y adecuada este año, es importante verificar que llegue igualmente al segundo piso de la Sala Isidora Zegers. Algunas interpretaciones fueron un tanto tímidas, y se pudo extraer más provecho musical de varias piezas. Por otro lado la calidad musical de las obras por momentos resulta bastante dispareja. Desearíamos que fuera más sólida, así como que hubiera más propuestas y aportes atrevidos en la elección y uso de lenguajes y materiales.

Reflexionando un poco más, nos preguntaremos qué es lo que motiva a tantos asistentes a desafiar el calor, el verano y lo extenso de algunos programas. ¿El éxito de público de este festival se debe a lo

1 Existe un breve análisis por Eduardo Cáceres en RMCh, LIX/203 (enero-junio, 2005), p. 30. 
heterogéneo de las obras? Es decir, sospechamos que la variedad de estilos y presentaciones posibilitan que "haya para todos los gustos" y que así "todos puedan salir contentos". O por el contrario, que el público terminará por "perderse" entre tanta variedad de la oferta. Pero quizás para auditores jóvenes en su mayoría, la superabundancia de estímulos provenientes de todos los rincones del planeta, producto de internet y de las redes sociales, es a lo que están habituados. Es tal vez nuestra concepción del sentido y lugar de lo contemporáneo la que está siendo desplazada.

Este Festival es un espacio importante para la vida musical chilena, probablemente porque lo que busca presentar no es la vanguardia -un intento históricamente frustrado y absorbido por el propio mercado del arte- sino es ir contra el olvido. Mientras presenciamos esta versión una pregunta recurrente era ¿Para qué hacer homenajes? ¿Para qué ligar este Festival a una supuesta tradición? ¿Es un Festival de música contemporánea el lugar para ello? Sin duda no hay una sola mirada para responder esto certeramente, y no es este el espacio para debatir sobre qué es lo contemporáneo en la música. No obstante, sí podemos entender que este es el sello del Festival, que lo caracteriza como un configurador de espacios de participación, en el que la memoria musical, junto a la memoria histórica, política y social entran todas a participar en la conformación de una vida universitaria. Un momento especial tuvo el final del último día en la Sala Isidora Zegers, cuando Eduardo Cáceres presentó en el escenario a todo el personal de sala, ovacionado por un público que los conoce en su cotidianeidad y que vio la excelente labor realizada. Un tanto extremo tal vez resultó el finalizar ese día con la entonación del himno de la Universidad de Chile, pero en este sentido, sin duda, esta versión se caracterizó por presentarse como "el festival de la memoria".

Fernanda Ortega 